\title{
Adjustable Amplification of Synaptic Input in the Dendrites of Spinal Motoneurons In Vivo
}

\author{
Robert H. Lee and C. J. Heckman \\ Departments of Physiology and Physical Medicine and Rehabilitation, Northwestern University Medical School, Chicago, \\ Illinois 60611
}

\begin{abstract}
The impact of neuromodulators on active dendritic conductances was investigated by the use of intracellular recording techniques in spinal motoneurons in the adult cat. The well known lack of voltage control of dendritic regions during voltage clamp applied at the soma was used to estimate dendritic amplification of a steady monosynaptic input generated by muscle spindle la afferents. In preparations deeply anesthetized with pentobarbital, la current either decreased with depolarization or underwent a modest increase at membrane potentials above $-40 \mathrm{mV}$. In unanesthetized decerebrate preparations (which have tonic activity in axons originating in the brainstem and releasing serotonin or norepinephrine), active dendritic currents caused strong amplification of la input. In the range of -50 to $-40 \mathrm{mV}$, peak la current was over four times as large as that in the pentobarbital-anesthetized preparations. Exogenous admin-
\end{abstract}

istration of a noradrenergic agonist in addition to the tonic activity further enhanced amplification (sixfold increase). Amplification was not seen in preparations with spinal transections. Overall, the dendritic amplification with moderate or strong neuromodulatory drive was estimated to be large enough to allow the motoneurons innervating slow muscle fibers to be driven to their maximum force levels by remarkably small synaptic inputs. In these cells, the main role of synaptic input may be to control the activation of a highly excitable dendritic tree. The neuromodulatory control of synaptic amplification provides motor commands with the potential to adjust the level of amplification to suit the demands of different motor tasks.

Key words: motoneuron; spinal cord; neuromodulation; electrophysiology; serotonin; norepinephrine; plateau potential; bistable; dendritic amplification
Voltage-sensitive conductances within the dendritic tree of the postsynaptic neuron play a major role in synaptic integration (Johnston et al., 1996; Yuste and Tank, 1996). Many types of voltage-sensitive conductances are under the control of neuromodulatory inputs acting via second messenger systems. Thus, the potential exists for the neuromodulatory inputs to control synaptic integration by altering the activation of voltage-sensitive currents in the dendrites of neurons.

The spinal motoneuron is subject to potent neuromodulatory control by axons that originate in the brainstem and release either serotonin (5-HT) or norepinephrine (NE) (Hounsgaard et al., 1988; Takahashi and Berger, 1990; Wang and Dun, 1990; White et al., 1991; Binder et al., 1996). In the presence of these neuromodulators, motoneurons exhibit a persistent inward current (Hounsgaard and Kiehn, 1989; Svirskis and Hounsgaard, 1998; Lee and Heckman, 1999a). The composition of this current may vary in different types of motoneurons (Hounsgaard and Kiehn, 1989; Hsiao and Chandler, 1995; Zhang et al., 1995; Lee and Heckman, 1998b). In spinal motoneurons in the adult cat, the total persistent inward current $\left(I_{\mathrm{PIC}}\right)$ is exceedingly large (Lee and Heckman, 1998a, 1999a). Activation of $I_{\text {PIC }}$ can produce prolonged selfsustained firing or, when spikes are blocked, long-lasting plateau potentials. Both of these phenomena can be subsequently deactivated by a brief inhibitory input, allowing the motoneuron to act in a bistable manner (Hounsgaard et al., 1988; Lee and Heckman, 1998a).

The dendritic tree of the spinal motoneuron is especially large, consisting of multiple primary trunks each with branches extending as far as $2 \mathrm{~mm}$ from the soma (for review, see Binder et al., 1996). Serotonergic receptors are densely distributed throughout this extensive dendritic tree (Alvarez et al., 1998). Similar data for nor-

Received May 2, 2000; revised June 13, 2000; accepted June 23, 2000.

This work was supported by National Institutes of Health Grants NS 34382 and NS 28076.

Correspondence should be addressed to Dr. C. J. Heckman, Department of Physiology M211, Northwestern University Medical School, 303 East Chicago Avenue, Chicago, IL 60611. E-mail: c-heckman@nwu.edu.

Copyright (C) 2000 Society for Neuroscience $0270-6474 / 00 / 206734-07 \$ 15.00 / 0$ adrenergic receptors are not yet available, but the high density of these receptors in the ventral part of the spinal cord (Giroux et al., 1999) suggests that the noradrenergic input also has a potent impact on the dendrites of spinal motoneurons. Most of $I_{\mathrm{PIC}}$ is generated in the dendritic tree (Hounsgaard and Kiehn, 1993; Lee and Heckman, 1998b, 1999b), where it can be readily affected by dendritic neuromodulatory receptors and where it may have a major impact on synaptic integration.

Our hypothesis was that the dendritic portion of $I_{\mathrm{PIC}}$ acts as a potent amplifier of steady-state synaptic input to spinal motoneurons, allowing even a small synaptic input to generate large currents at the soma of the cell. We further hypothesized that changes in the level of neuromodulatory drive to motoneurons would provide a control system for this highly potent dendritic amplification. These hypotheses were tested by the use of intracellular recordings in motoneurons in the lumbar spinal cord of the cat. Amplification of synaptic current was assessed with a single-electrode voltageclamp technique that controlled somatic voltage-sensitive conductances while assessing the impact of an excitatory synaptic input on the dendritic component of $I_{\text {PIC }}$.

\section{MATERIALS AND METHODS}

Surgical preparation. A total of 19 experiments were performed. Of these, 16 used an unanesthetized decerebrate preparation ( 3 of these were also spinalized), and 3 used a pentobarbital-anesthetized preparation. All procedures were approved by the animal care committee at Northwestern University. Full details are available in previous publications (Heckman et al., 1994; Lee and Heckman, 1998a). Briefly, all surgical preparations of the spinal cord and hindlimb were done under deep gaseous anesthesia (1.5$3.0 \%$ isoflurane in a $3: 1$ mixture of $\mathrm{O}_{2}$ and $\mathrm{N}_{2} \mathrm{O}$ ). The preparation included a laminectomy to expose the L7 and $\mathrm{S} 1$ segments of the cord for intracellular recording as well as isolation of the Achilles tendon and the nerves to the medial gastrocnemius (MG) and lateral gastrocnemius-soleus (LGS) muscles. In the decerebrate experiments, the gaseous anesthesia was discontinued after a precollicular decerebration in which all forebrain anterior to the colliculi was removed. In three of these experiments, the spinal cord was fully transected at the thoracic level (T9-T10). In three additional experiments, decerebration was not performed, and instead the animal was switched to pentobarbital anesthesia via intravenous administration of an initial dose of $65 \mathrm{mg} / \mathrm{kg}$. All preparations were then paralyzed with Flaxedil and artificially respired. In addition, a bilateral pneumothorax was done to enhance intracellular recording stability. In the pentobarbital- 


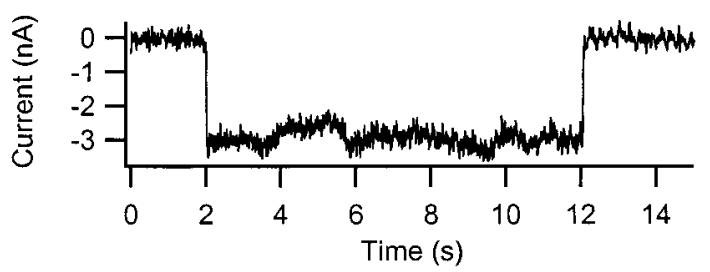

Figure 1. The monosynaptic input from muscle spindle Ia afferents generates prolonged and steady synaptic currents. Vibration was applied for 10 $\mathrm{sec}$ while the cell was clamped at $-60 \mathrm{mV}$.

anesthetized preparations, supplemental doses were given as needed to maintain a stable blood pressure and to provide continued absence of withdrawal reflexes, which were periodically tested by allowing the preparation to recover from paralysis. At the end of the experiment, the animals were killed with a lethal dose of pentobarbital.

Intracellular recordings of motoneurons. The nerves to the MG and LGS muscles in the hindlimb were placed on hook electrodes for stimulation. Intracellular recordings of motoneurons antidromically activated by stimulation of the MG and LGS nerves were obtained in the lumbar cord with sharp microelectrodes. Microelectrode tips were broken back under microscopic observation and control. Because of the large currents required for successful single-electrode voltage-clamp techniques in spinal motoneurons, resistances of the electrodes were kept low - typically $\sim 3-4 \mathrm{M} \Omega$ in saline before entering the cord. Electrodes were filled with a solution combining potassium citrate $(0.5 \mathrm{M})$ and potassium chloride $(1.5 \mathrm{M})$. Voltage clamp was achieved by the use of the discontinuous, singleelectrode voltage-clamp mode of our amplifier (Axoclamp 2A amplifier; Axon Instruments) (Finkel and Redman, 1985). Switching rates typically varied between 8 and $11 \mathrm{kHz}$. Head stage output was monitored at all times to assess settling of electrode transients. Data with inadequate settling were rejected. The clamp feedback gains ranged from 10 to $40 \mathrm{nA} / \mathrm{mV}$. In addition, feedback gain at low frequencies was increased to $100-400$ $\mathrm{nA} / \mathrm{mV}$ by adding an external low-frequency feedback loop $(-3 \mathrm{~dB}$ at 30 $\mathrm{Hz}$; gain of 10), which virtually eliminated steady-state errors in voltage (cf. Misgeld et al., 1989; Richter et al., 1996). Details of the limitations for this technique in motoneurons in vivo are in Lee and Heckman (1998b).

Levels of neuromodulatory input. The experimental design consisted of comparing three samples of cells obtained in three different experimental preparations, each with a different level of neuromodulatory drive. Withincell analyses were not performed because the agents used to alter the neuromodulatory state (the noradrenergic $\alpha_{1}$ agonist methoxamine and the anesthetic pentobarbital) were found in preliminary experiments to be slow acting and to produce small transient changes in blood pressure that destabilized intracellular recordings. The standard neuromodulatory state was defined as that existing in the decerebrate cat preparation, which has tonic activity in axons descending from the brainstem and releasing either 5 -HT or NE (Jankowska, 1992; Lee and Heckman, 1998b). $I_{\text {PIC }}$ is of moderate amplitude in this preparation (Lee and Heckman, 1999a). Administration of the noradrenergic $\alpha_{1}$ agonist methoxamine to the decerebrate preparation markedly increases the amplitude of $I_{\mathrm{PIC}}$ (Lee and Heckman, 1999a). Thus, we considered motoneurons in the decerebrate preparation with methoxamine to be in an enhanced neuromodulatory state as compared with the standard state for cells in the decerebrate without methoxamine. A minimal neuromodulatory state was defined by motoneurons from pentobarbital-anesthetized preparations, in which $I_{\text {PIC }}$ is small or nonexistent (Schwindt and Crill, 1980). In addition, a few motoneurons were recorded in fully spinalized decerebrate preparations to assess whether the amplification of synaptic input required descending input.

Synaptic input. Selective activation of muscle spindle Ia afferents provided an excitatory synaptic input that was primarily monosynaptic (Heckman and Binder, 1988) and widely distributed on motoneuron dendrites (Burke et al., 1979). It is likely that the Ia input is primarily ionotropic, but this has not been decisively established (see Discussion). Additionally, the Ia input is modest in amplitude, contributing perhaps 5\% of the total excitatory input to motoneurons (see Discussion), and in the adult cat, the Ia input is not mediated by NMDA receptors (Brownstone et al., 1994; Walmsley and Bolton, 1994; Miller et al., 1997).

Selective activation of the Ia input was achieved by high-frequency, low-amplitude sinusoidal vibration $(180 \mathrm{~Hz} ; 80 \mu \mathrm{m}$ peak-to-peak) of the combined MG and LGS tendons. The Ia synaptic current generated by the tendon vibration remained remarkably constant for up to $10 \mathrm{sec}$ (Fig. 1).

Protocols and analysis. In each cell, regardless of the preparation, the standard protocol began with measurement of a spike antidromically evoked by single shocks to either the MG or LGS nerves. The cell was tested for bistable behavior by applying a steady injected current in bridge balance mode to bring the cell near threshold for rhythmic firing. The bias level was monitored for 5-10 sec to verify that synaptic noise did not generate any spikes. A $1.5 \mathrm{sec}$ period of vibration that evoked Ia input was applied on this bias, and bistable behavior, if present, was manifest as self-sustained firing that continued after the vibration ceased. We then switched to voltage-clamp mode and applied a slow $(6-8 \mathrm{mV} / \mathrm{sec}) \mathrm{ramp}-$
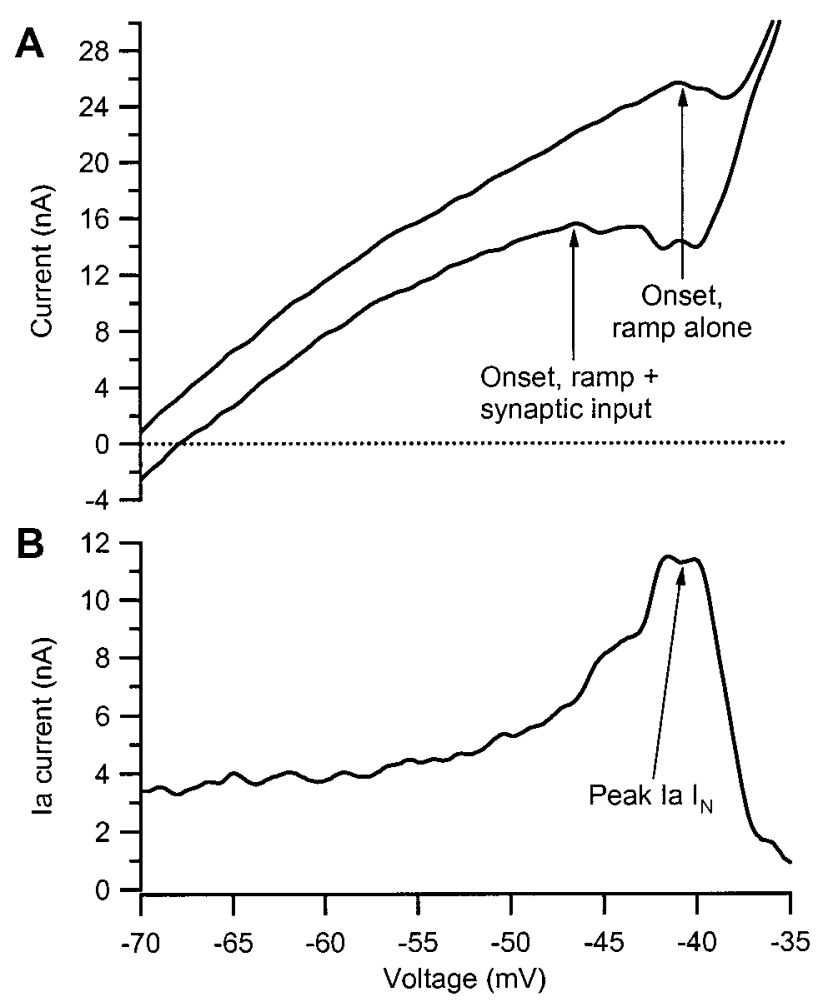

Figure 2. Measurement of the effect of active dendritic conductances on Ia synaptic input. The motoneuron illustrated is in the standard neuromodulatory state (see Materials and Methods). A, Top trace, The relationship between current and voltage generated by the use of single-electrode voltage clamp to apply a linearly rising voltage command that was slow enough to approximate steady-state conditions (Lee and Heckman, 1998b). The onset of $I_{\mathrm{PIC}}$ is evident as the start of a negative slope region. Bottom trace, The effect of applying a steady background of synaptic input from muscle spindle Ia afferents throughout the duration of the voltage ramp. Note the shift in onset of $I_{\mathrm{PIC}}$. $B$, Subtraction of the current in the bottom trace in $A$ from that in the top trace revealing the effective synaptic current generated at the soma by the Ia input (Ia $\left.I_{N}\right)$ as a function of voltage. In a passive neuron, Ia $I_{N}$ would have declined with voltage. Instead, Ia $I_{N}$ underwent strong amplification because of dendritic voltage-dependent conductances.

shaped voltage command to define the current-voltage ( $I-V)$ relationship of the cell. We have shown previously that this slow rate of change of voltage provides a good estimate of the cell's steady-state $I-V$ function (Lee and Heckman, 1998b). The same ramp voltage command was then repeated during a steady background of Ia input. The vibration began $1 \mathrm{sec}$ before the ramp to make sure that Ia input reached its steady-state level (see Fig. 1). The onset of the total $I_{\text {PIC }}$ was measured at the point of zero slope at the beginning of the negative slope region of the $I-V$ function (see Fig. $2 A$ ). The peak amplitude of $I_{\text {PIC }}$ was measured as the vertical distance from the peak downward deflection on the $I-V$ function to a line extrapolated from the subthreshold region to define the leak current. The primary analysis of the effect of Ia synaptic input on voltage-sensitive dendritic conductances was based on the current generated by the voltage ramps with and without the steady background of tendon vibration (see Results). Statistical analyses consisted of comparisons of sample averages using $t$ tests and linear regression analyses to assess the relationships between variables. The significance level $\alpha$ was set at $p=0.05$. When multiple $t$ tests were performed, 0.05 was divided by the number of $t$ tests.

\section{RESULTS}

Motoneurons were investigated under three preparations with different levels of neuromodulatory drive (see Materials and Methods): enhanced (decerebrate plus a noradrenergic agonist; $n=14$ ), standard (decerebrate with no drug; $n=12$ ), and minimal (pentobarbital anesthetized; $n=11$ ). In motoneurons in the standard state, application of a slow voltage ramp reveals an $I-V$ function with a region of negative slope, caused by a persistent inward current, $I_{\text {PIC }}$ (see Fig. $2 A$, top trace). The applied ramp was slow enough to approximate steady-state conditions (Lee and Heckman, 1998b). 


\section{Assessment of dendritic amplification of synaptic input}

To identify the influence of the Ia input on active dendritic currents, we relied on the well known lack of control of dendritic regions during voltage clamp applied to the soma of a neuron (Rall and Segev, 1985). This poor space clamp allows synaptic currents, most of which enter the cell via the dendrites, to alter the state of active dendritic conductances while the voltage clamp holds constant the behavior of somatic active conductances (Schwindt and Crill, 1995; Lee and Heckman, 1996). If $I_{\mathrm{PIC}}$ were generated solely in the portion of the cell under good clamp control, addition of a steady background of Ia synaptic input during the voltage ramp would simply shift the $I-V$ function downward along the current axis and slightly increase its overall slope. Instead, as illustrated by the cell in the standard state in Figure 2A, bottom trace, the Ia input altered the activation of voltage-sensitive dendritic currents and thus markedly lowered the onset voltage of $I_{\mathrm{PIC}}$. The difference between the top and bottom traces in Figure $2 A$ (which is shown in Fig. $2 B$ ) defines the total current generated at the soma of the cell by the Ia input, including the contribution of active dendritic currents. We refer to this total current as the Ia effective synaptic current (Ia $\left.I_{N}\right)$ (Binder et al., 1996). At hyperpolarized levels $(-70$ $\mathrm{mV})$, Ia $I_{N}$ was $\sim 3.5 \mathrm{nA}$, but this increased to over $11 \mathrm{nA}$ as the cell was depolarized to approximately $-42 \mathrm{mV}$. Thus, active dendritic currents caused the Ia synaptic input to undergo a strong, voltagedependent amplification. Further depolarization resulted in a sharp reduction in the magnitude of Ia $I_{N}$. Note also that the curvature of the $I-V$ function is increased in the presence of the Ia input (Fig. $2 A$, bottom trace), resulting in a gradual increase to the peak of amplification (Fig. $2 B$ ). This may reflect gradual activation of the dendritic component of $I_{\mathrm{PIC}}$. This pattern of a gradual increase to strong amplification followed by a clear reduction was typical of all cells in the standard and enhanced states (see below).

\section{Control of amplification by neuromodulatory drive}

Amplification of the Ia synaptic input was readily modified by the strength of the neuromodulatory drive to the motoneurons. Ia $I_{N}$ is plotted as a function of voltage for motoneurons in the three different neuromodulatory states in Figure 3. Both high- and lowinput conductance cells are shown for each state, because spinal motoneurons exhibit systematic differences in their electrical properties that correlate to differences in the mechanical properties of the muscle fibers they innervate (Binder et al., 1996) (see Discussion). In the enhanced neuromodulatory state (Fig. $3 A$ ), the peak Ia $I_{N}$ at depolarized levels was especially large. Further depolarization resulted in a precipitous decline that caused Ia $I_{N}$ to fall to zero. This suppression of Ia $I_{N}$ occurred well before the reversal potential of $0 \mathrm{mV}$ for the Ia synapses and probably was caused by activation of outward voltage-sensitive dendritic currents (cf. Clements et al., 1986; Hounsgaard and Kiehn, 1993; Powers and Binder, 2000). Note also that the amplification and suppression occurred at substantially more depolarized levels in the high-input conductance cell. In the standard state (Fig. 3B), the same amplification and suppression were still evident, but both were less dramatic. Furthermore, the differences in voltage range for lowversus high-input conductance cells remained well defined.

In the minimal state (Fig. 3C), the low-input conductance cell exhibited some amplification, but at a much more depolarized level than that for the low-input conductance cells in the enhanced and standard states. In some low-input conductance cells in the minimal state, the peak of amplification was not reached within the voltage range we could successfully clamp (data not shown). In contrast, most high-input conductance cells exhibited only voltagedependent suppression of Ia $I_{N}$. In the example in Figure $3 C$, Ia $I_{N}$ steadily declined to become negative at approximately $-37 \mathrm{mV}$, which, like the suppression after amplification in Figure 3, $A$ and $B$, presumably occurred because of activation of outward dendritic currents.

Six cells were examined in decerebrate preparations with full transections of the thoracic cord. Voltage-dependent amplification was not apparent in any of these six cells, regardless of whether they
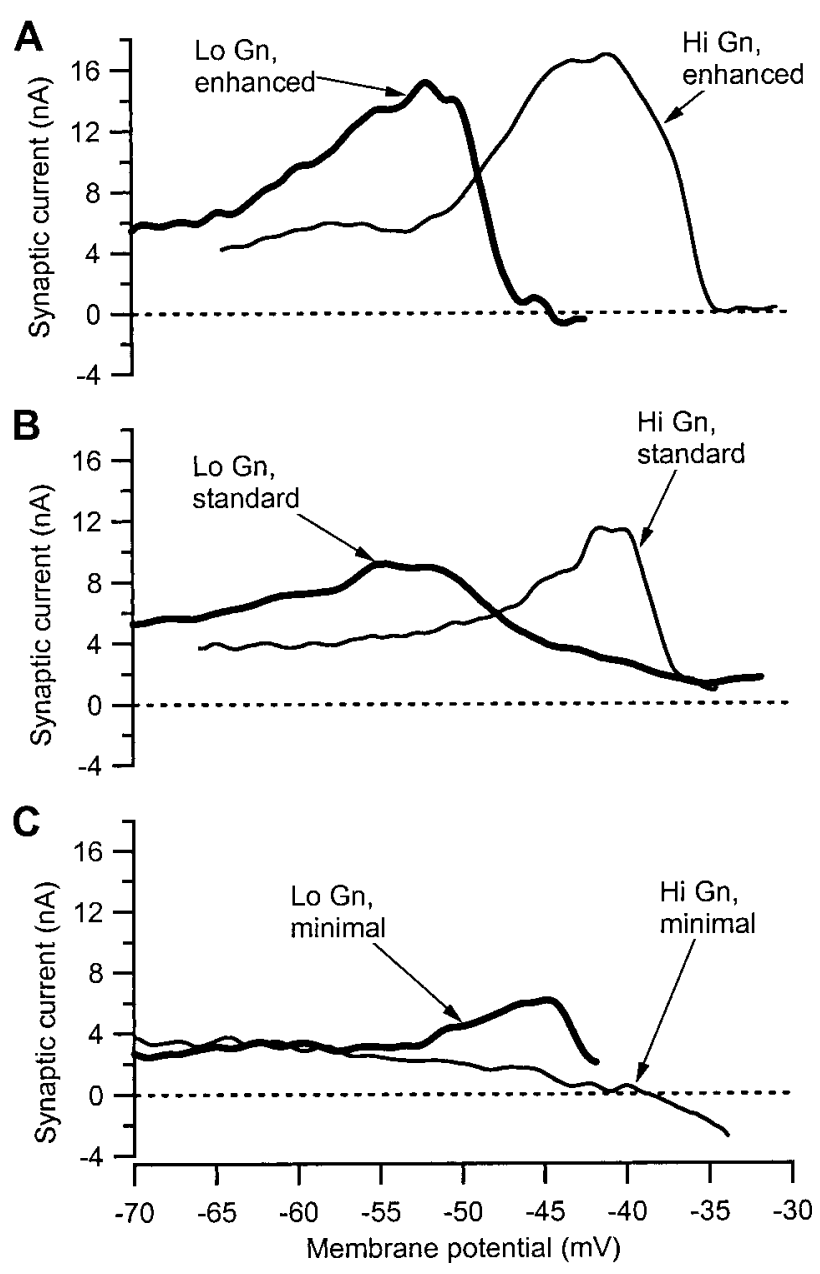

Figure 3. Changing neuromodulatory drive changed the amplification of Ia synaptic input. Each panel of the figure shows the changes in Ia $I_{N}$ as a function of voltage in two cells, one with low input conductance (thick line; Lo Gn) and one with high input conductance (thin line; Hi Gn). See Materials and Methods for techniques used to alter the neuromodulatory state of the cells. $A$, Amplification is highest in the enhanced neuromodulatory state. $B$, Amplification in the standard state is shown. $C$, Amplification is reduced or absent in the minimal state.

had high $(n=4)$ or low $(n=2)$ input conductances. Thus, like bistability (Hounsgaard et al., 1988), amplification of Ia input is probably dependent on neuromodulatory drive with a supraspinal origin.

Figure 4 shows the peak values of Ia $I_{N}$ for each cell plotted as a function of input conductance (in cells in the minimal state that lacked a clear maximum in Ia $I_{N}$, such as the one illustrated by the thin line in Fig. $3 C$, the peak value was defined as the average value of Ia $I_{N}$ between -50 and $-40 \mathrm{mV}$ ). The data for all three levels of neuromodulatory drive are illustrated, as indicated by the symbols in the legend. In the minimal state, Ia $I_{N}$ tended to decrease with input conductance (cf. Heckman and Binder, 1988), but this relationship was not significant. In contrast, Ia $I_{N}$ tended to increase with input conductance in both the standard and enhanced states, but only the relation for the standard state was significant $(r=0.75$; $p<0.01)$. The reason for the increase in amplification with input conductance is uncertain, but the most striking aspect of this figure is the existence of large overall increases in amplitude of Ia $I_{N}$ in the standard and enhanced states as compared with the minimal state. There was some overlap in the range of values for the standard state with those of the enhanced and minimal states. However, this overlap was not caused by interexperiment variability because the overlapping points were not all from the same experiment. Thus, in experiments in which three or more cells were included, the average within-experiment values for the minimal 


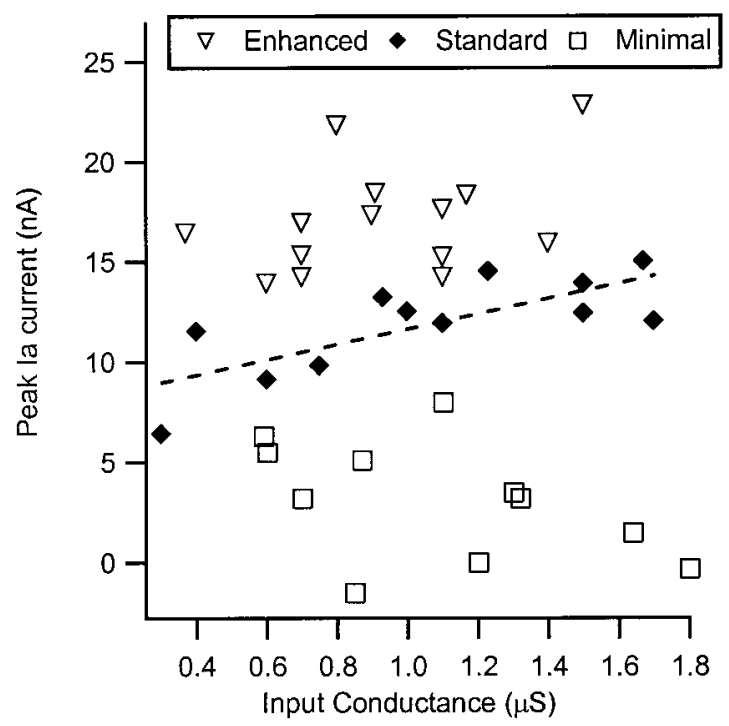

Figure 4. Peak Ia $I_{N}$ plotted as a function of input conductance for each cell in each neuromodulatory state (see legend symbols). Only the cells in the control state (Standard) exhibited a statistically significant relation between the two parameters (dashed line; $r=0.75 ; p<0.01$ ). There were however large differences in the values of peak Ia $I_{N}$ across the different states.

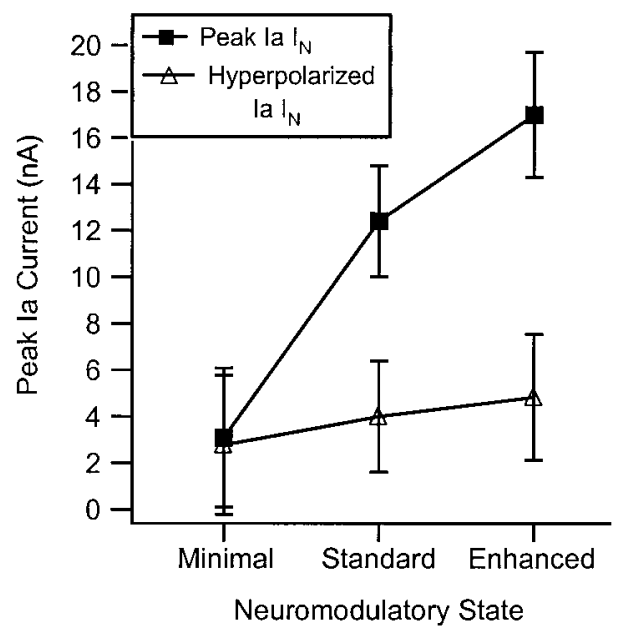

Figure 5. Comparison of peak Ia $I_{N}$, which occurs at depolarized levels (typically -50 to $-40 \mathrm{mV}$ ), with the Ia $I_{N}$ recorded at hyperpolarized levels $(-65$ to $-75 \mathrm{mV})$. Averages and SDs are given for the cells in each of the three neuromodulatory states listed on the $x$-axis. The hyperpolarized Ia $I_{N}$ reflected the influence of Ia input with reduced activation of voltagesensitive dendritic conductances. Thus the difference between peak and hyperpolarized points, which increases as neuromodulatory drive increases, gives an estimation of the influence of active dendritic currents. See Results for statistical comparisons.

and enhanced states fell outside the range of values for the standard state.

The average values for each neuromodulatory state are shown in Figure 5 . The peak Ia $I_{N}$ in the standard state $(11.9 \pm 2.4 \mathrm{nA})$ was approximately fourfold greater than that in the minimal state $(3.1 \pm 3.0 \mathrm{nA})$, whereas in the enhanced state the increase was approximately sixfold $(17.0 \pm 2.7 \mathrm{nA})$. All three averages were significantly different (minimal vs both standard and enhanced, $p<$ 0.00001 ; standard vs enhanced, $p<0.001$ ). Thus, neuromodulatory state had an enormous impact on the peak amplitude of Ia $I_{N}$.

\section{Magnitude of active dendritic currents}

The depolarization-induced amplification of Ia $I_{N}$ illustrated in Figures 2 and 3 was caused by activation of the component of $I_{\mathrm{PIC}}$ in poorly clamped, presumably dendritic, regions of the cell. To quantify the depolarization-induced changes attributable to dendritic conductances, we compared the amplitude of the Ia $I_{N}$ measured at the most hyperpolarized level in each cell (typically -65 to $-75 \mathrm{mV}$ ) with the peak amplitude recorded at more depolarized levels. We assumed that strong hyperpolarization at the soma would spread to the dendrites sufficiently to reduce markedly the activation of the dendritic component of $I_{\mathrm{PIC}}$ by the Ia input (cf. Schwindt and Crill, 1995; Lee and Heckman, 1996).

In the minimal state, peak Ia $I_{N}$ was, on average, approximately the same as the hyperpolarized Ia $I_{N}$, with modest amplification in some cells being counterbalanced by voltage-dependent suppression in other cells. In cells in the standard state, the difference between peak and hyperpolarized Ia $I_{N}$ was $7.8 \pm 2.1 \mathrm{nA}$, whereas in the enhanced state, this difference was $12.2 \pm 2.6 \mathrm{nA}$. Both values were significantly different from zero $(p<0.00001)$. Because of these differences, the peak Ia $I_{N}$ was $\sim 3.2$ times as large as the hyperpolarized Ia $I_{N}$ in the standard state and 3.5 times as large in the enhanced state.

However, Figure 5 also reveals a modest increase in the hyperpolarized Ia $I_{N}$ with increasing neuromodulatory drive (minimal, $2.8 \pm 0.8 \mathrm{nA}$; standard, $4.0 \pm 1.3 \mathrm{nA}$; and enhanced, $4.8 \pm 1.6 \mathrm{nA}$; only the difference between the minimal and enhanced state was significant, $p<0.001$ ). This increase was unlikely to be caused by an excitatory effect of the monoamines on Ia afferents via $\gamma$ motoneurons, because the preparation was paralyzed. Presynaptic actions of monoamines on muscle afferents are inhibitory and in any case appear to be absent on group I muscle afferents (Bras et al., 1990; Riddell et al., 1993). Thus, the increase probably occurred because the hyperpolarization was insufficient to prevent the Ia synaptic input from partially activating the dendrites in the standard and enhanced states. This suggests that amplification of Ia $I_{N}$ by dendritic currents is slightly larger than the estimates given above. Note also that the dendritic currents achieved their strong amplification despite reductions in synaptic driving force, which might have been quite large in dendritic regions.

It is interesting to note that the difference between peak Ia $I_{N}$ and the hyperpolarized Ia $I_{N}$ (i.e., the contribution from active dendrites) is $\sim 70 \%$ of the peak value of $I_{\mathrm{PIC}}$ as measured from the $I-V$ functions in both the standard and enhanced states (peak value for $I_{\mathrm{PIC}}$ in the standard state, $12.2 \pm 6.4 \mathrm{nA}$; enhanced state, $18.4 \pm$ $5.1 \mathrm{nA}$ ). The reason that the amplification of Ia input was usually smaller than $I_{\text {PIC }}$ may be that the synaptic input also activated voltage-sensitive outward currents in addition to $I_{\text {PIC }}$. However, in a few cells, including the one shown in Figure 2, the contribution from active dendrites was in fact larger than $I_{\text {PIC }}$. Thus the balance of outward and inward dendritic currents may well vary from cell to cell. These results support previous work indicating that most of $I_{\text {PIC }}$ is generated in dendritic regions. Overall, it is clear that voltage-dependent amplification attributable to dendritic voltagesensitive currents greatly increased Ia $I_{N}$ in both the standard and enhanced neuromodulatory states.

\section{Voltage range for amplification}

In all cells, the peak amplification of Ia $I_{N}$ occurred within the voltage range traversed during the interspike intervals of rhythmic firing in unclamped conditions in motoneurons (Schwindt and Crill, 1982). Figure 6 shows the voltage at the peak Ia $I_{N}$ plotted against input conductance for both the standard and enhanced state cells (this analysis could not be done for the minimal state as many cells lacked a clear peak). The peaks for low-input conductance cells were close to the threshold for spike initiation [typically approximately $-50 \mathrm{mV}$ (Lee and Heckman, 1998b)], whereas those for high-input conductance cells were more depolarized but still did not exceed the voltage range traversed during higher rates of rhythmic firing. The relationship between voltage level for peak amplification and input conductance was significant for both the enhanced and standard states, but the slightly increased slope for the enhanced state was not significantly steeper than that for the standard state. Thus, methoxamine mainly increased the potency of the amplification without altering its voltage range, which is con- 

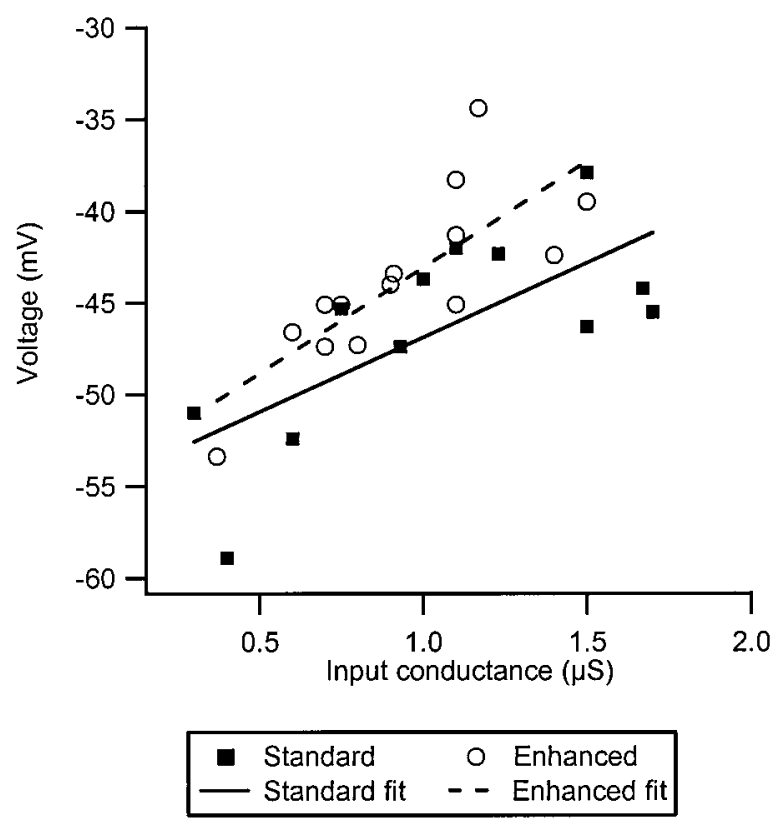

Figure 6. The voltage for peak amplification of Ia synaptic input varied systematically with the input conductance of the motoneuron. In the sample of cells in the standard neuromodulatory state, there was a statistically significant trend for amplification to occur at more depolarized levels in high-input conductance cells $(r=0.71 ; n=12 ; p<0.05$; slope, 8.15; intercept, -55.02). A similar relationship was observed in the sample of cells in the enhanced neuromodulatory state $(r=0.78 ; n=14 ; p<0.01$; slope, 11.54; intercept, -54.59). The difference between the slopes for the standard and enhanced states was not significant $(p>0.05, t$ tests for slopes).

sistent with our previous work showing that methoxamine did not alter the voltage range for activation of $I_{\text {PIC }}$ (Lee and Heckman, 1998b).

\section{Consistency of synaptic amplification}

Only 3 of the 14 cells in the enhanced neuromodulatory state exhibited strong bistable behavior. As in our previous study, these 3 cells had low input conductances (Lee and Heckman, 1998a). None of the 12 cells in the standard state was bistable, which is again consistent with our previous work (Lee and Heckman, 1999a). However, every cell in both the enhanced and standard states exhibited strong amplification of Ia synaptic input. Thus, amplification of synaptic input may play a wider role in normal motor outflow than bistable behavior.

\section{Firing rates evoked by la synaptic input}

We also measured the firing rate evoked during the Ia input in the test for bistable firing. As expected from the strong amplification of Ia $I_{N}$ seen in every cell in the standard and enhanced states, Ia-evoked firing rates in all cells in these states were remarkably high. In the standard state, the firing rate averaged $31 \pm 11 \mathrm{~Hz}$, whereas in the enhanced state the average was even higher at $60 \pm$ $15 \mathrm{~Hz}$. These rates are entirely consistent with our previous work (Lee and Heckman, 1998a).

\section{DISCUSSION}

The results shown here indicate that potent amplification of maintained synaptic input can occur in the dendrites of motoneurons and that this amplification scales with the level of neuromodulatory drive. Previous studies have shown that the transient Ia EPSP evoked by a single electrical shock does not undergo significant amplification with depolarization in the decerebrate preparation (Brownstone et al., 1994). Polysynaptic transient inputs do undergo amplification, but unlike the Ia input, these inputs are probably mediated by NMDA receptors (Brownstone et al., 1994). Transient inputs may be insufficient to activate $I_{\mathrm{PIC}}$, which appears to require a more sustained input for activation (Hounsgaard and Kiehn, 1989; Bennett et al., 1998b; Lee and Heckman, 1998b). Voltagedependent synaptic amplification has been observed previously in response to sustained EPSPs from muscle stretch (Bennett et al., 1998a) and tendon vibration (Powers and Binder 2000), followed by suppression at more depolarized levels. However, in the present study, the use of voltage clamp has allowed us to show that voltagesensitive currents in the dendrites play a major role in generating this amplification and suppression of sustained inputs and that this dendritic amplification scaled with neuromodulatory drive.

Several roles for the effect of dendritic voltage-sensitive conductances on synaptic integration have been advanced (Stuart and Sakmann, 1994; Schwindt and Crill, 1997; Cook and Johnston, 1999; Magee, 1999). However, three aspects of our results suggest that unusually large dendritic voltage-sensitive currents in motoneurons do not just modify synaptic current but instead completely transform synaptic integration in these cells.

(1) Relatively small synaptic inputs were very effective in activating the dendritic component of $I_{\text {PIC }}$. The Ia input constitutes perhaps $5 \%$ of the total excitatory synaptic input to spinal motoneurons [the total number of excitatory synapses on spinal motoneurons in the cat is $\sim 17,000-50,000$ (Ornung et al., 1998); the total number of Ia synapses from MG and LGS spindles is $\sim 1000$ (estimated from Burke et al., 1979)]. Nonetheless, the dendritic voltage-sensitive currents activated by the Ia input were large in comparison with the total persistent inward current in motoneurons (i.e., the current added to Ia $I_{N}$ by depolarization-induced amplification was $60-70 \%$ of $I_{\mathrm{PIC}}$ ).

(2) The peak Ia $I_{N}$ was several times larger than the Ia $I_{N}$ at the most hyperpolarized levels. Thus, the current generated by dendritic voltage-sensitive conductances was several times larger than the current generated by the Ia synaptic input on its own.

(3) The amplified Ia $I_{N}$ generated very high firing rates. In the minimal state, Ia $I_{N}$ is only large enough to increase motoneuron rates by $5-8 \mathrm{~Hz}$ (Powers and Binder, 1995). In contrast, firing rates to Ia input reached $>30 \mathrm{~Hz}$ in the standard state and $>50 \mathrm{~Hz}$ in the enhanced state. These rates are compared with those required for maximum force generation in the next section.

\section{Differences in synaptic integration between low- and high-input conductance motoneurons}

Slow-twitch (type S) muscle fibers require firing rates of $20-30 \mathrm{~Hz}$ to reach their maximum force (Binder et al., 1996). The current required to bring type $\mathrm{S}$ motoneurons to threshold in the standard and enhanced states is small because the monoamines also produce significant steady depolarization (Binder et al., 1996; Lee and Heckman, 1998a). Therefore the firing rates during Ia input in low-input conductance cells usually required no bias current or, in the enhanced state, a negative bias because the cell fired tonically in the resting state (Lee and Heckman, 1998a). Thus, a single synaptic input system becomes capable of driving type $\mathrm{S}$ motoneurons to their maximum functional firing rates (standard state) or beyond (enhanced state).

Therefore, it appears that type $\mathrm{S}$ motoneurons in both the standard and enhanced states have a unique form of synaptic integration. Ionotropic synaptic inputs are primarily relieved of the burden of supplying sufficient current to drive rhythmic firing. Instead, these inputs activate a highly excitable dendritic tree, which is then the primary source of current to generate firing. This new form of synaptic integration stands in sharp contrast to the classical picture for motoneurons, which was developed from studies in the minimal state and postulated that simultaneous activation of many synaptic inputs was required to achieve high firing rates (Binder et al., 1996).

High-input conductance motoneurons tend to innervate fasttwitch (type F) muscle fibers. Because of their higher input conductances, type $\mathrm{F}$ motoneurons are recruited after type $\mathrm{S}$ motoneurons-this is Henneman's size principle (Henneman and Mendell, 1981; Binder et al., 1996). Type F fibers require much higher rates than do S fibers to reach maximum, often $70 \mathrm{~Hz}$ or more (Binder 
et al., 1996). Furthermore, although voltage thresholds for spike initiation are similar in all motoneurons (Pinter et al., 1983; Lee and Heckman, 1998b), the higher input conductance of the type F cells means that they require much more current to reach threshold, as much as 10-20 nA compared with $3 \mathrm{nA}$ or less in type S cells in the standard state (Lee and Heckman, 1998a). In addition, in high-input conductance cells, amplification is shifted to a more depolarized level than in S cells (Fig. 4). These considerations suggest that the type $\mathrm{F}$ motoneurons with the highest input conductances have a broad subthreshold and near-threshold range in which the integration of multiple inputs is necessary to produce strong firing. Overall these systematic differences in synaptic integration in types $\mathrm{S}$ and $\mathrm{F}$ motoneurons further emphasize the importance of Henneman's size principle (Henneman and Mendell, 1981; Binder et al., 1996) in understanding motor outflow.

\section{Neuromodulatory control of amplification in motoneurons}

The large differences between synaptic amplification in the different neuromodulatory states could provide descending motor commands with the capacity to adjust amplification of ionotropic inputs for different motor tasks (cf. Svirskis and Hounsgaard, 1998). The Ia input does appear to be ionotropic (Binder et al., 1996), but we cannot exclude the possibility that it activates some metabotropic glutamate receptors or that Ia afferents colocalize neuromodulatory transmitters. However, amplification was not present in the spinalized state, so that any neuromodulatory actions of Ia afferents on their own must be ineffective without descending monoaminergic input. Thus, the descending monoaminergic input can potentially be used to control amplification in motoneurons during normal motor behaviors. For example, one might expect that highly precise tasks might benefit from reduced amplification to avoid overemphasis of small errors in the descending commands. Tasks requiring moderate force like posture might have moderate amplification, whereas tasks requiring high forces might require as much amplification as possible.

\section{Limitations and further studies}

In the simple combination of voltage-clamp and synaptic input used in this study, a full range description of the influence of dendritic voltage-sensitive currents on synaptic integration was achieved with a compact protocol. This technique makes efficient use of what was considered previously a serious limitation of voltage-clamp methods in neurons, namely, the lack of space clamp in dendritic regions. However, there is a clear limitation with this method, which is the uncertainty regarding what portion of the cell was under good clamp control. The finding that amplification of Ia $I_{N}$ was large relative to the total $I_{\mathrm{PIC}}$ suggests that the controlled portion was rather small, perhaps not even including the proximal dendrites. Nor is it clear to what degree the monoamines actually increase the amplitude of persistent inward currents in the dendrites as compared with decreasing outward currents. Blocking $\mathrm{K}^{+}$ currents with intracellularly injected agents increases the amplitude of both transient and sustained Ia EPSPs (Clements et al., 1986; Powers and Binder, 2000). One possibility may be that reduction of a proximally located outward current markedly facilitates transfer of current to the soma. However, a localized proximal reduction does not appear to be consistent with the lack of effect of methoxamine on both the voltage for peak amplification (Fig. 6) and the voltage for onset of $I_{\text {PIC }}$ (Lee and Heckman, 1998b), because improved current transfer should aid the somatically applied clamp currents in depolarizing the dendrites. Perhaps a distributed reduction of outward currents allows the persistent inward current to dominate the dendrites. These issues require further study with in vitro preparations and computer simulations (cf. Booth et al., 1997).

There are however many additional questions that need to be pursued in vivo. The time course of amplification may be important, because $I_{\text {PIC }}$ tends to decay slowly in type F but not in type S cells (Lee and Heckman, 1998b). Closely linked to the question of whether synaptic amplification is gradable is the question of how amplification impacts the summation of several different synaptic inputs. Preliminary data indicate in fact that summation of amplified inputs is linear (Prather et al., 1998). Further work is needed on inputs mediated by metabotropic or NMDA glutamate receptors and, especially, on inhibitory inputs. The complex interplay among various inputs should allow descending motor commands ample scope for controlling the potent amplification of synaptic inputs mediated by voltage-sensitive conductances in the dendrites of motoneurons.

\section{REFERENCES}

Alvarez FJ, Pearson JC, Harrington D, Dewey D, Torbeck L, Fyffe RE (1998) Distribution of 5-hydroxytryptamine-immunoreactive boutons on alpha-motoneurons in the lumbar spinal cord of adult cats. J Comp Neurol 393:69-83.

Bennett DJ, Hultborn H, Fedirchuk B, Gorassini M (1998a) Synaptic activation of plateaus in hindlimb motoneurons of decerebrate cats. J Neurophysiol 80:2023-2037.

Bennett DJ, Hultborn H, Fedirchuk B, Gorassini M (1998b) Short-term plasticity in hindlimb motoneurons of decerebrate cats. J Neurophysiol 80:2038-2045.

Binder MD, Heckman CJ, Powers RK (1996) The physiological control of motoneuron activity. In: Handbook of physiology. Exercise: regulation and integration of multiple systems (Rowell LB, Shepherd JT, eds), pp 1-53. New York: Oxford UP.

Booth V, Rinzel J, Kiehn O (1997) Compartmental model of vertebrate motoneurons for $\mathrm{Ca} 2+$-dependent spiking and plateau potentials under pharmacological treatment. J Neurophysiol 78:3371-3385.

Bras H, Jankowska E, Noga B, Skoog B (1990) Comparison of effects of various types of NA and 5-HT agonists on transmission from group II muscle afferents in the cat. Eur J Neurosci 2:1029-1039.

Brownstone RM, Gossard J-P, Hultborn H (1994) Voltage-dependent excitation of motoneurones from spinal locomotor centres in the cat. Exp Brain Res 102:34-44.

Burke RE, Walmsley B, Hodgson JA (1979) HRP anatomy of group Ia afferent contacts on alpha motoneurones. Brain Res 160:347-352.

Clements JD, Nelson PG, Redman SJ (1986) Intracellular tetraethylammonium ions enhance group Ia excitatory post-synaptic potentials evoked in cat motoneurones. J Physiol (Lond) 377:267-282.

Cook EP, Johnston D (1999) Voltage-dependent properties of dendrites that eliminate location-dependent variability of synaptic input. J Neurophysiol 81:535-543.

Finkel AS, Redman SJ (1985) Optimal voltage clamping with single microelectrode. In: Voltage and patch clamping with microelectrodes (Smith TG, Lecar H, Redman SJ, Gage PW, eds), pp 95-120. Bethesda, MD: American Physiological Society.

Giroux N, Rossignol S, Reader TA (1999) Autoradiographic study of alpha1- and alpha2-noradrenergic and serotonin1A receptors in the spinal cord of normal and chronically transected cats. J Comp Neurol 406:402-414.

Heckman CJ, Binder MD (1988) Analysis of effective synaptic currents generated by homonymous Ia afferent fibers in motoneurons of the cat. J Neurophysiol 60:1946-1966.

Heckman CJ, Miller JF, Munson M, Paul KD, Rymer WZ (1994) Reduction in postsynaptic inhibition during maintained electrical stimulation of different nerves in the cat hindlimb. J Neurophysiol 71:2281-2293.

Henneman E, Mendell LM (1981) Functional organization of motoneuron pool and its inputs. In: Handbook of physiology, the nervous system, motor control (Brooks VB, ed), pp 423-507. Bethesda, MD: American Physiological Society.

Hounsgaard J, Kiehn O (1989) Serotonin-induced bistability of turtle motoneurones caused by a nifedipine-sensitive calcium plateau potential. J Physiol (Lond) 414:265-282.

Hounsgaard J, Kiehn O (1993) Calcium spikes and calcium plateaux evoked by differential polarization in dendrites of turtle motoneurones in vitro. J Physiol (Lond) 468:245-259.

Hounsgaard J, Hultborn H, Jespersen B, Kiehn O (1988) Bistability of alpha-motoneurones in the decerebrate cat and in the acute spinal cat after intravenous 5-hydroxytryptophan. J Physiol (Lond) 405:345-367.

Hsiao CF, Chandler SH (1995) Characteristics of a fast transient outward current in guinea pig trigeminal motoneurons. Brain Res 695:217-226.

Jankowska E (1992) Interneuronal relay in spinal pathways from proprioceptors. Prog Neurobiol 38:335-378.

Johnston D, Magee JC, Colbert CM, Cristie BR (1996) Active properties of neuronal dendrites. Annu Rev Neurosci 19:165-186.

Lee RH, Heckman CJ (1996) Influence of voltage-sensitive dendritic conductances on bistable firing and effective synaptic current in cat spinal motoneurons in vivo. J Neurophysiol 76:2107-2110.

Lee RH, Heckman CJ (1998a) Bistability in spinal motoneurons in vivo: systematic variations in rhythmic firing patterns. J Neurophysiol $80: 572-582$. 
Lee RH, Heckman CJ (1998b) Bistability in spinal motoneurons in vivo: systematic variations in persistent inward currents. J Neurophysiol 80:583-593.

Lee RH, Heckman CJ (1999a) Enhancement of bistability in spinal motoneurons in vivo by the noradrenergic alpha1 agonist methoxamine J Neurophysiol 81:2164-2174.

Lee RH, Heckman CJ (1999b) Paradoxical effect of QX-314 on persistent inward currents and bistable behavior in spinal motoneurons in vivo. J Neurophysiol 82:2518-2527.

Magee JC (1999) Dendritic Ih normalizes temporal summation in hippocampal CA1 neurons. Nat Neurosci 2:508-514.

Miller JF, Paul KD, Rymer WZ, Heckman CJ (1997) Intrathecal 2-amino-7-phophonohetanoic acid (AP-7) attenuates clasp knife reflex in decerebrate cat. Soc Neurosci Abstr 23:1039.

Misgeld U, Muller W, Polder HR (1989) Potentiation and suppression by eserine of muscarinic synaptic transmission in the guinea-pig hippocampal slice. J Physiol (Lond) 409:191-206.

Ornung G, Ottersen OP, Cullheim S, Ulfhake B (1998) Distribution of glutamate-, glycine-, and GABA-immunoreactive nerve terminals on dendrites in the cat spinal motor nucleus. Exp Brain Res 118:517-532.

Pinter MJ, Curtis RL, Hosko MJ (1983) Voltage threshold and excitability among variously sized cat hindlimb motoneurons. J Neurophysiol 50:644-657.

Powers RK, Binder MD (1995) Effective synaptic current and motoneuron firing rate modulation. J Neurophysiol 74:793-801.

Powers RK, Binder MD (2000) Summation of effective synaptic currents and firing rate modulation in cat spinal motoneurons. J Neurophysiol 83:483-500.

Prather JF, Powers RK, Cope TC (1998) Relation between effective synaptic current and firing rate modulation in medial gastrocnemius motoneurons studied in the decerebrate cat. Soc Neurosci Abstr 24:911.

Rall W, Segev I (1985) Space clamp problems when voltage clamping branched neurons with intracellular microelectrodes. In: Voltage and patch clamping with microelectrodes (Smith TG, Lecar H, Redman SJ, Gage PW, eds), pp 191-215. Bethesda, MD: American Physiological Society.
Richter DW, Pierrefiche O, Lalley PM, Polder HR (1996) Voltage-clamp analysis of neurons within deep layers of the brain. J Neurosci Methods 67:121-123.

Riddell JS, Jankowska E, Eide E (1993) Depolarization of group II muscle afferents by stimuli applied in the locus coeruleus and raphe nuclei of the cat. J Physiol (Lond) 461:723-741.

Schwindt PC, Crill WE (1980) Properties of a persistent inward current in normal and TEA-injected motoneurons. J Neurophysiol 43:1700-1724.

Schwindt PC, Crill WE (1982) Factors influencing motoneuron rhythmic firing: results from a voltage-clamp study. J Neurophysiol 48:875-890.

Schwindt PC, Crill WE (1995). Amplification of synaptic current by persistent sodium conductance in apical dendrite of neocortical neurons. J Neurophysiol 74:2220-2224.

Schwindt PC, Crill WE (1997) Modification of current transmitted from apical dendrite to soma by blockade of voltage- and $\mathrm{Ca} 2+$-dependent conductances in rat neocortical pyramidal neurons. J Neurophysiol 78:187-198.

Stuart GJ, Sakmann B (1994) Active propagation of somatic action potentials into neocortical pyramidal cell dendrites. Nature 367:69-72.

Svirskis G, Hounsgaard J (1998) Transmitter regulation of plateau properties in turtle motoneurons. J Neurophysiol 79:45-50.

Takahashi T, Berger AJ (1990) Direct excitation of rat spinal motoneurones by serotonin. J Physiol (Lond) 423:63-76.

Walmsley B, Bolton PS (1994) An in vivo pharmacological study of single group Ia fibre contacts with motoneurones in the cat spinal cord. J Physiol (Lond) 481:731-741.

Wang MY, Dun NJ (1990) 5-Hydroxytryptamine responses in neonate rat motoneurones in vitro. J Physiol (Lond) 430:87-103.

White SR, Fung SJ, Barnes CD (1991) Norepinephrine effects on spinal motoneurons. In: Progress in brain research (Barnes CD, Pompeiano O, eds), pp 343-350. Amsterdam: Elsevier.

Yuste R, Tank DW (1996) Dendritic integration in mammalian neurons, a century after Cajal. Neuron 16:701-716.

Zhang B, Wooten JF, Harris-Warrick M (1995) Calcium plateau potentials in crab stomatogastric ganglion motor neuron. II. Calcium-activated slow inward current. J Neurophysiol 74:1938-1946. 